\section{As Práticas de Leitura Literária e a Literatura Infantil no Acervo do Estágio de Formação do Educador em Serviço - EFES: Resultados e Análises Preliminares de um Projeto de Pesquisa e Extensão Universitária}

\author{
The Literary Reading Skills and the Children's Literature \\ in the Archives of Internship in Formation of the Educator \\ in Service - EFES: Preliminary Results and Analysis of a \\ University Research and Extension Project
}

\section{RESUMO}

O presente artigo se propõe a expor os resultados preliminares desta pesquisa de Iniciação Científica que procura obter elementos e fontes que contribuam para uma melhor compreensão das práticas de leitura literária e formação de leitores bem como da presença (ou ausência) da literatura infantil na escola pública brasileira entre as décadas de 1980 e 1990. Por meio da identificação, organização e análise do Acervo do Estágio de Formação do Educador em Serviço - EFES, procuramos reconstituir o que Chervel [2] e Julia [5] chamam de "história das disciplinas escolares", no que diz respeito ao ensino da língua portuguesa e literatura, bem como a própria história desse complexo e longo projeto de pesquisa e extensão universitária. Uma primeira abordagem e análise desse arquivo já nos permite compreender seu potencial para futuras pesquisas, bem como nos possibilitou resgatar as publicações da equipe EFES durante seu período de existência. Apresentaremos uma síntese da primeira triagem dessa documentação, que constituirá nosso corpus documental.

Palavras-chave: Práticas de Leitura. Literatura Infantil. Ensino de Literatura. História da Educação.

\section{ABSTRACT}

This paper intends to expose the preliminary results of this undergraduate research, which pursues elements, sources and reflections that contribute with a better understanding of literary reading skills and reader formation, as well as a finer comprehension of the presence (or absence) of children's literature in Brazilian public schools between 1980 and 1990. Through identification, organization and analysis of the EFES's archives, we sought to reconstitute what Chervel [2] and Julia [5] call history of school subjects on Portuguese language and literature teaching, as well as the very history of this long and complex research and extension project. A first

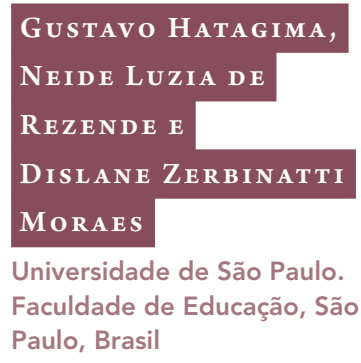

Paulo, Brasil 
approach and analysis of this archive has allowed us to comprehend its potential for further research. Moreover, it has enabled us to salvage the publications of EFES's team during its period of existence. We will present a synthesis of the first sorting of this documentation, which will constitute our documental corpus.

Keywords: Reading Skills. Children's Literature. Literature Teaching. History of Education.

\section{INTRODUÇÃO}

O presente artigo apresenta os resultados parciais de uma Iniciação Científica que está inserida no projeto de pesquisa Memória e História da Formação de Professores de Lingua Materna e Literatura: O Acervo EFES - Estágio de Formação do Educador em Serviço (1984-1996), sob a coordenação das Profas. Dras. Neide Luzia de Rezende e Dislane Zerbinatti Moraes. Nosso objetivo é compreender as práticas de leitura literária e a literatura infantil na escola pública de São Paulo, nas décadas de 1980 e 1990, e, para alcançar tal objetivo, utiliza-se o Acervo do Estágio de Formação do Educador em Serviço (EFES) como fonte documental. Tal arquivo também nos leva a refletir como a Universidade Pública guarda a memória de projetos de extensão ocorridos no passado. Como ideias, propostas e trabalhos que visaram contribuir na relação entre a pesquisa e trabalho acadêmicos são preservados? Esta é uma das perguntas que movem nossa pesquisa, ainda em processo, e que aqui pretendemos expor.

Atualmente localizado na Faculdade de Educação da Universidade de São Paulo, o Acervo EFES é constituído por uma diversa gama de documentos, variando no tipo (cartas, relatórios, livros, teses, materiais didáticos etc.) e em quem produziu (a própria equipe EFES, Ministério da Educação, professores da Educação Básica e etc.). Nossa pesquisa pretende realizar uma primeira abordagem desse arquivo, fruto de anos de trabalho e pesquisa, na intenção de resgatar e conservar essa memória da educação brasileira. Seguimos o que o historiador Carlos Bacellar [1] pontuou sobre a preservação e o resgate de um conjunto documental extremamente rico e que ainda permanece fora de um arquivo público:

A documentação de caráter privado pode dizer respeito a acervos de pessoas, de famílias, grupos de interesse (militantes políticos, instituições, clubes etc.) ou de empresas. No Brasil não há uma prática corriqueira de preservação documental privada, e as notícias de destruição de importantes conjuntos documentais infelizmente não são raras (p. 42).

O Estágio de Formação do Educador em Serviço (EFES) foi um complexo e longo programa de formação-pesquisa coordenado pela Profa. Dra. Lígia Chiappini M. Leite, dentro da linha Literatura e Educação do Departamento de Teoria Literária e Literatura Comparada da FFLCH-USP. Seus antecedentes remontam a um período de trabalho das associações docentes, pois o embrião do que viria a ser o EFES nasceu entre 1979 e 1980 dentro da Associação de Professores de Língua e Literatura (APLL), por meio de um grupo de trabalho para formação permanente dos docentes 
que conciliava professores universitários, professores da educação básica, graduandos de Letras e estudantes de Magistério. Segundo Soares [6] e Faria [3], essa foi uma das formas de organização possíveis naquele contexto de intensas reflexões sobre o rumo do país, de entrada de novas discussões e referenciais teóricos sobre o ensino da língua portuguesa, bem como de reformulações curriculares, para tentar modificar e recuperar uma escola cheia de inúmeros problemas e deficiências. Na década de 1980, em um Brasil em processo de redemocratização, a relação entre a Universidade e a escola pública se intensificou e o EFES pode ser visto como exemplo desse caminho tomado.

Iniciado em 1984, como um projeto participante do Programa de Integração da Universidade com o Ensino de $1^{\circ} \mathrm{Grau}^{*}$, do MEC/SESu., e passando por diversas etapas até 1997, o EFES ministrou cursos para formação continuada de professores da Educação Básica, organizou seminários, publicou livros dando voz aos docentes da escola pública e participou intensamente da reorientação curricular da Secretaria Municipal de Educação de São Paulo (SME-SP), entre os anos de 1989 e 1992. Com o projeto intitulado A circulação de textos na escola, iniciado em 1992 e indo até o término do projeto, por volta de 1996/1997, revisitou as escolas que aderiram ao projeto de interdisciplinaridade, proposto pela reorientação curricular da SME-SP. Ainda em 1996, o EFES foi convidado a dar seu parecer sobre os Parâmetros Curriculares Nacionais de Língua Portuguesa.

O desafio colocado diante de nós é, então, também compreender a relação entre os diversos agentes que, direta ou indiretamente, participaram do período de existência do projeto. Entre professores universitários, professores das redes municipal e estadual de São Paulo, pesquisadores de pós-graduação e alunos de graduação da USP, que formavam a equipe, surgem também instituições de financiamento de pesquisa e órgãos públicos da área da Educação.

Portanto, por meio desta pesquisa esperamos colaborar: (1) para a organização da documentação pertencente ao acervo, de modo a ampliar as possibilidades de acesso e pesquisa; e (2) para a análise desse acervo, contribuindo para o entendimento do lugar que o EFES ocupa dentro da história das práticas de ensino de língua portuguesa e literatura.

Para nortear os modos de trabalho em arquivos, utilizamos as contribuições de Bacellar [1], em especial no que diz respeito às práticas de pesquisa. No auxílio da compreensão e reconstituição da história das práticas escolares, apoiou-se em Julia [5], para entender a cultura escolar enquanto objeto histórico e os cuidados metodológicos necessários com as fontes documentais, e Chervel [2], que mostra, a partir do estudo da história das disciplinas escolares, a complexidade e criatividade da escola na constituição e manutenção de suas disciplinas. Consideramos que através da reconstituição da história das disciplinas escolares é possível:

*Em 1986, este programa foi integrado ao programa Nova Universidade. 
(...) identificar, tanto através das práticas de ensino utilizadas na sala de aula como através dos grandes objetivos que presidiram a constituição das disciplinas, o núcleo duro que pode constituir uma história renovada da educação. Ela abre, em todo caso, para retomar uma metáfora aeronáutica, a 'caixa preta' da escola, ao buscar compreender o que ocorre nesse espaço particular ([5], p. 13).

Compreendemos que esse arquivo guarda uma documentação que propicia a aproximação à história das práticas culturais - no caso, as práticas escolares, mais especificamente, àquelas referentes ao período das décadas de 1980 e 1990 da história da educação brasileira.

\section{MATERIAIS E MÉTODOS}

Para organizar o trabalho, a pesquisa foi dividida em quatro etapas: (1) identificação dos documentos que constituem o acervo, por meio de categorias como nome do documento, autor(es) e data, entre outros**; (2) preservação e manutenção das fontes, realizadas por meio da limpeza dos armários e troca das caixas originais (de plástico/ poliondas) por caixas de papelão; (3) seleção dos documentos que serão objetos da análise; e (4) realização desta análise documental.

No tempo a que corresponde este artigo, foram realizadas as duas primeiras etapas e iniciou-se o processo de triagem, referente à terceira etapa.

Embora um dos nossos objetivos iniciais fosse a identificação dos documentos, realizando uma primeira abordagem do acervo, o ponto central era estabelecer um primeiro contato e compreender este arquivo da melhor maneira possível. Assim, é provável que não tenha sido possível apreender este conjunto documental e as fontes individualmente em toda a sua complexidade, uma vez que para isso é essencial debruçar-se com profundidade. No entanto, como era previsto, os resultados parciais deste trabalho servem como uma primeira aproximação com o objeto da investigação, que são as práticas de leitura e a literatura infantil no Ensino Fundamental I.

A ideia inicial era utilizar como fonte primária os diários de campo, que deram origem aos três primeiros volumes da coleção Ensinar e Aprender com Textos ${ }^{* * *}$, mas com a descoberta de outros livros, frutos do trabalho do EFES e materiais relacionados, perguntamo-nos se deveríamos ou não ampliar o escopo da pesquisa. Por outro lado, como os diários são a produção final do EFES, possuindo informações claras e precisas que remontam a um processo de trabalho mais bem registrado e de mais fácil acesso, é mais provável que se mantenha o rumo original, deixando essas outras possibilidades para um segundo momento de pesquisa - já facilitado por esta primeira abordagem e análise.

\footnotetext{
**A saber, todas as categorias: localização; tipo de documento; quantidade; nome/descrição; autor(es); data; qualidade e; observações.

***Esses diários de campo constituíram a base dos primeiros volumes da coleção Aprender e ensinar com textos, publicada pela editora Cortez e que hoje se encontram no Acervo EFES.
} 
Com o conhecimento, ainda que não aprofundado, dessas primeiras fases do EFES, poderemos registrar a potencialidade de pesquisa e as contribuições do caminho empreendido. Segundo Bacellar [1], isso se torna essencial uma vez que é parte do trabalho do historiador conscientizar e alertar para a importância dos arquivos, cabendo a ele (ou a quem está trabalhando nesses arquivos, como é o caso desta pesquisa), no momento em que acessa os documentos, "(...) o papel fundamental de alertar para sua importância, pressionando por melhores atenções para com os registros do passado” (p.38).

\section{RESULTADOS PARCIAIS}

O trabalho realizado até o presente momento permitiu obter os seguintes resultados parciais: (1) identificar e organizar todo o Acervo EFES; (2) recuperar uma série de artigos e livros produzidos pela equipe durante os anos de existência do projeto e que estavam esquecidos; (3) dar início ao processo de triagem de documentos que formarão o corpus documental desta pesquisa; iniciando, assim, (4) a recuperação da própria história deste projeto, bem como dos trabalhos realizados e dos referenciais utilizados.

A complexidade do projeto, que atravessou mais de uma década, possuindo diversas faces e modos de abordagem da formação de professores e ensino da língua portuguesa, é o ponto mais marcante dessa primeira aproximação da documentação. Além disso, em virtude do contato com toda a papelada do arquivo e com leituras que permitiram o início da reconstituição do período histórico no qual o EFES estava inserido, evidenciaram-se as próprias dificuldades, burocracias e desafios de projetos que tentam realizar a ponte entre a Universidade e a educação básica.

Estas questões, nem sempre explícitas, encontram-se nos diversos tipos de fontes presentes no acervo, arquivo que guarda uma documentação de naturezas diferentes, marcando, portanto, não apenas o próprio processo de trabalho do EFES, como também a um universo próprio e mais amplo de questões da educação brasileira. Neste momento, registramos quem são os produtores dessa documentação, organizando-os em cinco grandes grupos: a equipe EFES (coordenadores, pós-graduandos, graduandos); o Estado e suas instituições (ministérios, secretarias); professores da educação básica; a universidade, seus pesquisadores e professores; editoras e autores de livros didáticos.

A partir dessa organização, procuramos também explicitar as categorias da documentação produzida: relatórios e diários de campo; assessorias do EFES a outras instituições (MEC, SME-SP, escolas particulares); materiais do processo de constituição das produções bibliográficas (versões de capítulos, transcrições, relatórios de professores da educação básica e de monitores, questionários aplicados a professores e alunos); documentação dos cursos ministrados (listas de presença, relatórios dos participantes e etc.); correspondência (entre órgãos/instituições oficiais para o projeto, destes órgãos/instituições para um público geral - por exemplo, relatórios de programas do MEC/SESu, da escola para a família); publicações oficiais; atividades utilizadas em sala de aula (coletadas durante as observações e cursos); artigos, livros 
e capítulos de livros de diversos autores, usados como referencial teórico em cursos, seminários e para discussão interna; teses e dissertações; artigos e textos jornalísticos de revistas e jornais; materiais didáticos escolares (apostilas e livros); e outros documentos (anotações, listas de presença de reuniões etc.).

A quantidade desses documentos não é equivalente, sendo, por exemplo, muito mais significativo o número de relatórios e diários de campo do que de materiais didáticos escolares. Alerta-se aqui para o grande número de indícios deixados por essa vasta documentação****. Nesse sentido, um tópico que chamou a atenção foram os questionários aplicados a professores, pela equipe coordenada pelo Prof. Dr. Adilson Citelli, que nos levam a pensar que houvesse talvez o desejo de o EFES continuar para além do ano em que foi interrompido. Esses questionários foram realizados na fase final do EFES, A circulação de textos na escola, a qual culminou com a publicação da trilogia Aprender e Ensinar com Textos - cujo volume 3 foi elaborado pela equipe de Citelli -, mas não estão explicitados nessa produção. Além disso, um dos relatórios traz uma observação feita no Ensino Médio, que até então não havia sido alvo das pesquisas. São apenas indícios, uma vez que não foram e nem serão por ora investigados a fundo, pois o objeto desta pesquisa são os anos iniciais do Ensino Fundamental I. Porém, esse breve episódio ilustra mais uma das possibilidades do Acervo.

As descobertas relativas ao que aqui se nomeia como "bibliografia recuperada do EFES” também constituíram um momento central, pois nos servem para ter um ponto de apoio nas reflexões: de um lado, a documentação mais "crua" de todo o processo; do outro, a sistematização e impressões da própria equipe em relação a seu trabalho, pesquisa, intenções e objetivos.

Como um projeto de longa duração e que contou com a participação de diversos professores universitários, professores da educação básica e pesquisadores de pós-graduação e graduação, o EFES, durante seu período de atividades, produziu uma diversa gama de livros, artigos e capítulos de livros, que trazem tanto elementos da sua história e constituição, como relatos e reflexões do trabalho desenvolvido. Porém, aproximadamente 15 anos depois de seu término, pouco desta produção bibliográfica continua sendo lida e conhecida. A seguir, a lista das publicações encontradas até o presente momento ${ }^{* * * * *}$

\footnotetext{
****Ginzburg [4] chama a atenção para a sensibilidade aos pequenos sinais e aos indícios, a um trabalho histórico constituído como uma investigação de detetive.

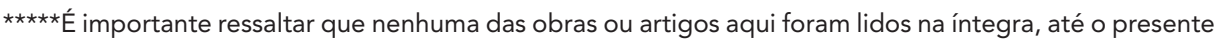
momento. Portanto, as impressões registradas neste artigo referem-se a uma leitura superficial e que combina um conhecimento empírico permitido pela experiência no acervo.
} 


\section{Língua e literatura: $O$ professor pede a palavra}

Valéria de Marco, Ligia Chiappini Moraes Leite, Suzi Frankl Sperber (orgs.)

Ano: 1981 - Editora Cortez

Coletânea de textos apresentados pela Associação de Professores de Língua e Literatura (APLL), na ocasião da XXXII Reunião Anual da Sociedade Brasileira para o Progresso da Ciência, em 1980. O grupo de professores, incluindo Ligia Chiappini, que procurou refletir sobre a formação de professores e o ensino da língua portuguesa e literatura pode ser considerado um primeiro passo/esboço para o que seria o EFES.

\section{Reinventando o diálogo: Ciências e humanidades na formação do professor}

Ligia Chiappini Leite, Maria Helena Martins, Maria Lúcia Z. de Souza (orgs.) Ano: 1987 - Editora Brasiliense

Primeiro livro publicado pela Equipe EFES. É a combinação das comunicações apresentadas no I Encontro de Professores Universitários com Trabalho junto ao $1^{\mathrm{o}}$ e $2^{\mathrm{o}}$ Graus e no III Seminário Aberto do Estágio de Formação do Educador em Serviço, realizados em 1986.

\section{Quando o professor resolve: Experiências no ensino de português}

Regina Maria Hubner (org.) e Ligia Chiappini (supervisão)

Ano: 1989 - Editora Loyola

O foco deste livro são os professores da Educação Básica que participaram de cursos ministrados pelo EFES. É uma coletânea de relatos destes professores, comentados e debatidos por professores universitários.

\section{Coleção Aprender e ensinar com textos (volumes 1, 2 e 3 )}

Ligia Chiappini (coord. geral), João Wanderley Geraldi e Beatriz Citelli (coords. vol. 1), Helena Brandão e Guaraciaba Micheletti (coords. vol. 2), Adilson Citelli (coord. vol. 3) Ano da $1^{a}$ edição: 1995 - Editora Marca D’água

Ano da $2^{\text {a }}$ edição: 1997 - Editora Cortez

A obra mais difundida do EFES foi fruto de reflexão posterior à experiência da reorientação curricular ocorrida na Secretaria Municipal de Educação de São Paulo, entre os anos de 1989 e 1992. A equipe fez uma pesquisa-ação para refletir sobre a circulação de textos na escola. A descoberta aqui apresentada é a existência de uma primeira edição, preliminar, de 1995, que foi lida e analisada por professores da educação básica, e depois finalizada para publicação definitiva em 1997. 


\section{ARTIGOS E/OU CAPÍTULOS DE LIVROS}

Até o presente momento foram identificados quatro artigos e/ou capítulos de livros: 1) O papel da Universidade brasileira nas escolas públicas: uma experiência alternati$v a^{* * * * * *}$, de Ligia Chiappini Moraes Leite; 2$)$ Ao pé do texto na sala de aula******, de Ligia Chippini Moraes Leite e Regina Maria Hubner Marques; 3) Interdisciplinaridade na escola pública: a experiência paulista na gestão de Paulo Freire e a participação da universidade $e^{* * * * * * *}$, de Ligia Chiappini, José Luiz Miranda e Marcela Cristina Evaristo; e 4) A circulação de textos na escola: primeiros resultados ${ }^{* * * * * * * *}$, de João Wanderley Geraldi, Ligia Chiappini, Guaraciaba Micheletti e Adilson Citelli. É importante frisar que o processo de pesquisa e catalogação ainda está em andamento, portanto as referências que aqui se encontram disponíveis ainda não estão devidamente normatizadas.

Sabe-se que tal produção, especialmente no que diz respeito a artigos, pode ser maior do que a encontrada até agora. De qualquer modo, fica a reflexão de como os trabalhos realizados por professores e/ou projetos no passado chegam até os dias atuais. Como essas experiências passadas são (ou não) aproveitadas, se esses regis-

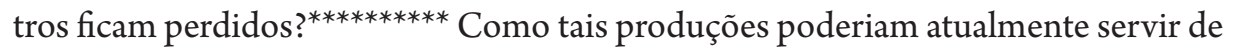
base para reflexões aprofundadas, na graduação e na pós-graduação, para diversos fins (ensino da língua portuguesa, formação de professores, história da educação e etc.)?

A partir de tais dados, foi possível realizar a primeira triagem do que constituirá o corpus documental desta pesquisa. De toda a documentação disponível, agora já identificada, iniciamos, no mês de janeiro de 2014, a primeira triagem, buscando selecionar quais serão as fontes que entrarão como nosso corpus documental. Neste momento foi essencial relembrar qual é o objeto da pesquisa: as práticas de leitura e a literatura infantil nos anos iniciais Ensino Fundamental. Esta retomada se mostra extremamente importante, uma vez que, quando da escrita do projeto, a nossa visão sobre o que o Acervo permitiria era menor do que o encontrado, o que não configura, ao nosso ver, nenhum problema. Com estas informações reconstituídas em mãos, iniciou-se o processo de triagem, pois:

\footnotetext{
******In: Revista da Faculdade de Educação, n 12, jan/dez. São Paulo, 1986.

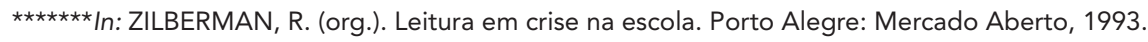

$\star \star \star \star \star \star \star \star$ In: FAUNDEZ, A. (org.) Educação, desenvolvimento e cultura. São Paulo: Cortez, 1994.

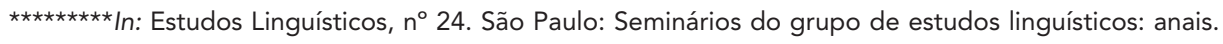
1995.
$\star \star \star \star \star \star \star \star \star \star$ Esta reflexão claramente se baseia no Projeto EFES, ou seja, tem-se a noção de que diversos projetos ocorrem de diversas formas. Mas, ao mesmo tempo, acredita-se que tal ponto é importante para colocar-nos a pensar sobre os aprendizados com as experiências do passado, de forma a melhorar projetos atuais e/ou futuros.
} 
Munido de armas e precauções dispostas anteriormente, de conhecimento prévio sobre o assunto (...), o pesquisador está pronto para prosseguir na análise e na interpretação de suas fontes. Já pode cotejar informações, justapor documentos, relacionar texto e contexto, estabelecer constantes, identificar mudanças e permanências e produzir um trabalho de História ([1], p. 71).

Como primeira triagem, optamos por uma seleção ampla, resultado de uma coleta de tudo o que, aparentemente, pode entrar como documentação a ser analisada futuramente. Quatro grandes categorias de documentos constam nesta primeira abordagem, lembrando que a essa seleção preliminar não precedeu a leitura integral de todos os documentos, portanto é provável que parte dessa documentação não seja inserida no corpus desta pesquisa. Além dessas fontes, os livros Aprender e ensinar com textos - vol. 2 e Quando o professor resolve também entram na primeira triagem. As quatro categorias de documentos são: 1) Diários de campo - diários de campo dos pesquisadores da fase $A$ circulação de textos na escola; 2) Relatórios - relatórios dos pesquisadores da fase $A$ circulação de textos na escola; 3 ) Atividades de sala de aula; 4) Questionários - os questionários fazem parte da pesquisa coordenada pelo professor Adilson Citelli. São dados sobre os professores da educação básica e suas relações com as diversas mídias. Tais dados podem vir a interessar, pois há uma parte das respostas que se referem a professores polivalentes ( $\left.1^{\circ} \mathrm{Grau}\right)$.

\section{ANÁLISES PARCIAIS}

Como a pesquisa ainda não se encontra finalizada, o que será apresentado aqui é uma análise preliminar. No entanto, já é possível iniciar o processo de reflexão e reconstituição da abordagem das práticas de leitura e a presença e/ou ausência da literatura infantil na escola do período de existência do EFES (1984-1997).

Conforme Chervel [2], as disciplinas escolares possuem uma existência autônoma, isso porque são criadas pela, na e para a escola, e se constituem por meio de um processo cumulativo de camadas sucessivas. No nosso intuito de compreender as práticas escolares de leitura no âmbito dessa concepção de história das disciplinas escolares, acreditamos que a documentação guardada durante os mais de dez anos do projeto possivelmente revelarão como isso se deu em relação aos conteúdos disciplinares do primeiro grau da época, sobretudo em relação à questão da leitura, cujos novos paradigmas de trabalho didático atuais parecem ter dificuldade em romper com os velhos paradigmas que persistem e se reproduzem. Essa abordagem histórica das metodologias e práticas de ensino procura, justamente, revelar essas etapas históricas que se superpõem possivelmente no ensino seja na prática ou no discurso.

Compreendemos que o Acervo EFES traz essa possibilidade, uma vez que o arquivo lá guardado remete tanto à gênese (como foram produzidas e criadas), às funções (suas finalidades) e o próprio funcionamento (seus efeitos e como ocorre a aculturação) da disciplina escolar Português. Claro que, ao mesmo tempo, sabemos que são poucos os materiais de alunos. Desse modo, nossa observação não ocorrerá de modo direto. Encontraremos observações, análises e interpretações de outros pesquisadores 
(situados num tempo e espaço específico, com objetivos igualmente pertencentes a esse tempo e espaço).

Por isso mesmo, conforme Dominique Julia [5], é essencial um cuidado metodológico com estas fontes documentais, pois:

Convém, pelo contrário, a cada vez, recontextualizar as fontes das quais podemos dispor, estar conscientes de que a grande inércia que percebemos em um nível global pode estar acompanhada de mudanças muito pequenas que insensivelmente transformam o interior do sistema; convém ainda não nos deixarmos enganar inteiramente pelas fontes, mais frequentemente normativas, que lemos. A história das práticas culturais é, com efeito, a mais difícil de se reconstituir porque ela não deixa traço; o que é evidente em um dado momento tem necessidade de ser dito ou escrito? (p. 15)

Além disso, ainda apoiados em Julia, uma pesquisa desta ordem exige que se relacione o estudo das normas e finalidades vigentes, as condições do profissional professor - visto em perspectiva histórica - e os conteúdos ensinados, compreendendo, neste último ponto, que as disciplinas não são meramente vulgarizações nem adaptações das ciências de referência e trazem consigo uma criação escolar, que ainda está relacionada a uma "liberdade prática" dos professores em suas práticas (e por isso Chervel coloca a disciplina escolar como uma criação autônoma da escola).

Esta pesquisa não tem a intenção de fazer uma análise que abarque tantos elementos, principalmente pelo tempo que temos, mas é importante citar tais indicações na medida em que este trabalho é apenas um pequeno passo em direção à constituição da história da disciplina Português. É essencial ter tanto uma cautela e uma sensibilidade apurada, conforme Ginzburg [4], para enxergar importância naquilo que aparentemente é tão automático e natural que se tornou marginal. Pois justamente esses pormenores negligenciados é que poderão revelar as práticas e sua real presença na escola daquele período, pois:

(...) a existência de uma profunda conexão que explica os fenômenos superficiais é reforçada no próprio momento em que se afirma que um conhecimento direto de tal conexão não é possível. Se a realidade é opaca, existem zonas privilegiadas - sinais, indícios - que permitem decifrá-la ([4], p. 177).

É justamente na busca por tais zonas privilegiadas, que possibilitem dissolver a opacidade da realidade, que reside uma das fontes de importância do acervo constituído. Lá se encontram diários de campo resultados de observações etnográficas realizadas pela Equipe EFES no começo da década de 1990. Pressupomos que tal documentação guarda elementos que foram, à época, cotejados e analisados, mas provavelmente também haja neles pontos que podem ter passado despercebidos. São tais fontes que poderão contribuir para a apreensão de um momento precioso da história da educação brasileira, as décadas de 1980 e 1990, ao trazer as ideias, as propostas e as relações existentes na escola pública brasileira e também estabelecidas entre a universidade e a educação básica. Ao que diz respeito a essa relação, nos anos de 1980, no contexto das reformas curriculares, Faria [3] aponta: 
Inicialmente, conforme observamos, ocorreu um estreitamente das relações entre as universidades, equipes técnicas das Secretarias de Educação e professores das redes, o que proporcionou uma readequação dos currículos para atender à nova demanda escolar, por meio de proposições cujo objetivo era dinamizar o tratamento dos conteúdos com renovado embasamento teórico (p. 74).

O próprio EFES, conforme explicitado na Introdução, esteve próximo das Secretarias de Educação do Município e do Estado de São Paulo, também participando de algumas reorientações curriculares. No mínimo, essas múltiplas facetas do projeto evidenciam um grande comprometimento com esses propósitos de mudança e transformação (re)nascidos na época da abertura da ditadura militar e vividos intensamente durante as décadas de 1980 e 1990. Cabe a nós entender qual foi o grau de relevância e importância do EFES no mundo acadêmico e escolar. Há algum indicativo para além do próprio acervo? Quem ou quais outros projetos ele influenciou? Podemos tomar o EFES como um indicativo das práticas daquele período?

Por meio dessas questões, o trabalho realizado até aqui nos levou a refletir sobre a complexa relação entre a universidade e a escola - primeiramente no que tange às práticas, aos estudos e às pesquisas sobre metodologia de ensino - e permeada por fatores políticos e outras instituições, como as agências de financiamento, que também se mostram complicadas e evidenciam uma grande rede de interesses e influências muitas vezes invisíveis ou opacas.

Além disso, outra dificuldade se evidencia no nosso trabalho: escrever uma história do tempo presente institui-se como um grande desafio a ser transposto. $\mathrm{O}$ trabalho no acervo revelou os percalços para reconstituir essa história recente, pois, mesmo que o EFES tenha sido interrompido há pouco mais de quinze anos, as questões em que eles trabalhavam ainda continuam muito vivas. Surgiram diversos questionamentos quanto a este ponto: como resgatar essa memória recente, dada a dificuldade colocada pela falta de um distanciamento temporal maior? Como pode ser feita a manutenção desta memória, para que projetos, quando finalizados, não desapareçam com toda a sua contribuição, seus avanços, propostas e resultados?

A manutenção dessa memória é essencial para que o trabalho da Universidade, pelo menos aqui neste contexto, possa aproveitar toda essa experiência anterior. Pois verificar que este arquivo que estava "esquecido" levanta a questão de como estão e se existem outros arquivos deste tipo, que poderiam também contribuir para o fortalecimento da educação brasileira e de seus instrumentos de preservação, que ainda são muito poucos. Assim, mesmo que indiretamente, esta pesquisa também serve de inspiração para que haja um resgate histórico de outros projetos na área da Educação. Aparentemente menor, nosso projeto não conseguiu apoio por ocasião do edital Memória da USP, em 2012.

\section{CONCLUSÕES}

Com a diversa gama de informações possíveis de serem observadas e registradas parece-nos inevitável pontuar o potencial variado que esse acervo guarda para futuras 
pesquisas da área da Educação, embora nós mesmos não possamos precisar toda sua capacidade para pesquisas de cunho histórico. Os tópicos apresentados neste artigo são talvez apenas os mais visíveis neste momento. A relação da Universidade com a educação básica; a constituição, a história e entraves existentes em projetos universitários; as políticas públicas e as reorientações curriculares; e a formação de professores (principalmente a contínua e em serviço) são portas de entrada que pudemos vislumbrar até o momento. Mas a quantidade de material que seguirá inexplorado ao fim da pesquisa, bem como sua amplitude, que vai além da pesquisa acadêmica (correspondência e materiais de assessoria curricular, por exemplo), indicam as outras possibilidades deste arquivo.

As descobertas trazidas pelo trabalho cotidiano de pesquisa se constituíram em um elemento vivaz, que contribui diretamente para o prazer da busca e da investigação. Esta sensação vai ao encontro do que diz Bacellar [1]:

Aventurar-se pelos arquivos, portanto, é sempre um desafio de trabalhar em instalações precárias, com documentos mal acondicionados e preservados, e mal organizados. Portanto, o historiador tem sempre pela frente o desafio de permanecer por meses, quando não por anos, nesses ambientes pouco acolhedores em termos de conforto e de condições de trabalho, mas em um esforço que quase sempre levará a alcançar resultados muito gratificantes. Encontrar os documentos que servem ao tema trabalhado é uma sensação que todos que passaram pela experiência recordam com prazer, e os move a novamente retornar à pesquisa. (p. 49, grifo nosso).

Nosso trabalho tem sido gratificante e de extremo aprendizado, por isso acreditamos que as etapas seguintes do nosso trabalho, o fechamento do corpus documental e a sua análise, virão nos possibilitar uma nova visão e compreensão do ensino da língua portuguesa, assim como abrirá este rico acervo para outras pesquisas, de modo a resgatar e conservar a memória da educação brasileira bem como de projetos de extensão universitária.

\section{REFERÊNCIAS}

[1] BACELLAR, C. O uso e o mau uso dos arquivos. In: PINSKY, C. B. (org.) Fontes históricas. São Paulo: Contexto, pp.23-79, 2008.

[2] CHERVEL, A. História das disciplinas escolares: Reflexões sobre um campo de pesquisa. Teoria \& Educação, Porto Alegre, n. 2, pp. 177-229, 1990.

[3] FARIA, V. F. S. de. O ensino de literatura: Articulação entre propostas oficiais e pesquisa universitária. 2009, 126p. Dissertação (Mestrado em Educação) - Faculdade de Educação, Universidade de São Paulo, São Paulo, 2009.

[4] GINZBURG, C. Sinais: Raízes de um paradigma indiciário. In: Mitos, emblemas, sinais: Morfologia e história. São Paulo: Cia. das Letras, pp. 143-179, 2007.

[5] JULIA, D. A cultura escolar como objeto histórico. Revista Brasileira de História da Educação, São Paulo, n. 1, pp. 9-43, jan.-jun. 2001. 
[6] SOARES, M. Português na escola: História de uma disciplina curricular. In: BAGNO, M. (org.). Lingüística da norma. São Paulo: Edições Loyola, pp. 155-177, 2004.

GUSTAVo hATA gIMA graduando em Pedagogia da Faculdade de Educação da Universidade de São Paulo (FE-USP)_e-mail: gustavo.hatagima@usp.br

Neide luZiA De ReZende professora do Departamento de Metodologia do Ensino e Educação Comparada da Faculdade de Educação da Universidade de São Paulo (FE-USP) - e-mail: neirez@usp.br

Dislane Zerbinatti moraes professora do Departamento de Metodologia do Ensino e Educação Comparada da Faculdade de Educação da Universidade de São Paulo (FE-USP) - e-mail:dzmoraes@usp.br 